\title{
Identification of Failure Years by Modification of Yield Model in Isapur Reservoir, India
}

\author{
Kalpeshkumar M. Sharma1, Deepak V. Pattewar', P. D. Dahe ${ }^{2}$ \\ ${ }^{1}$ Civil Engineering Department, MGM's College of Engineering, Nanded, India \\ ${ }^{2}$ Civil-Water Management Department, S.G.G.S's College of Engineering and Technology, Nanded, India \\ Email: kalpeshkumar sharma@yahoo.com, deepak pattewar@yahoo.co.in
}

Received 13 September 2014; revised 11 October 2014; accepted 2 November 2014

Copyright (C) 2014 by authors and Scientific Research Publishing Inc.

This work is licensed under the Creative Commons Attribution International License (CC BY). http://creativecommons.org/licenses/by/4.0/

c) (i) Open Access

\begin{abstract}
The failure years for a desired annual reliability of a water use were prespecified in the yield model. These failure years were identified prior to the solution of the model by observing the critical period in the given annual flow record. Some initial trials of the yield model were usually sufficient to identify the failure years. Simulation can be employed for exact identification of these failure years. A method for determination of failure years through the yield model is presented in this paper, as an alternative to simulation. The yield model employing this method is useful when the reliability of water use is to be considered as a decision variable. The method for determination of failure years by yield model is adopted for further analysis and compare with the simulation model, one of the failure year is not matching with the common set of failure years in the simulation model.
\end{abstract}

\section{Keywords}

Yield Model, Simulation Model, Isapur Reservoir

\section{Introduction}

In the system analysis, which may involve the use of mathematical models (linear programming (LP)) and simulation, is a set of powerful tools to solve design and operation problems in water resources. In the literature, a number of studies on system analysis techniques appear which explore a given system in depth and provide useful information. These techniques are being increasingly applied to the real life problems as a result of wider application of computers, availability of software and better understanding of the approach. 
The evaluation of the storage-yield and the operational performance of a reservoir form an important part in the study of water resources development. Application of the modeling for reservoir system analysis involves studies especially to reevaluate storage-yield and operation performance for existing reservoir systems. Such periodic evaluation may be required to assess the responsiveness of a system to prevailing conditions and demands arising out of ever changing water use patterns. A simulation model provides a rapid means to evaluate the performance of a system. It accurately assesses the system yield for an assumed set of operating rules. It does not assess the maximum yield that can be achieved by adopting the best possible set of operating rules for the system. Yields obtained from optimization techniques can be useful in the planning of new resources, wherein accurate prediction of future yields can be difficult because of the lack of defined operating rules for the new system. On the other hand, simulations are more realistic in terms of representing system behavior and offer better solutions than optimization models. Although, the LP based optimization models (yield model) can solve large size problems, they are approximate representation of the system.

Jacoby and Locks [1] proposed the combined use of optimization and simulation model for the planning of Delware river basin. Viessman et al. [2] combine optimization and simulation in a procedure to select the most efficient arrangement of components for regional water resources development and management policy. The technique is applied to the Elkhon river basin in Nebraska. Loucks et al. [3] developed the yield model which is a general purpose implicitly stochastic LP model that incorporates several approximations to reduce the size of the constraint set needed to describe reservoir system operation and to capture the desired reliability target releases. A basic problem with the implicitly stochastic models is that many periods may need to be included in a model if an adequate distribution of unregulated natural stream flows is to result. This can be avoided in part by designing for the "critical period" of record Hall et al. [4].

Loucks et al. [3] demonstrated that in several cases the yield model provides a reasonable estimate of the distribution of reservoir capacity requirements obtained with the sequent peak algorithm. Dandy, G.C. and Connarty, M.C. and Loucks, D.P. [5] made a comparison of simulation, network linear programming, full optimization LP model and the LP yield model for estimating the safe yield of the Canberra water supply system consisting of four reservoirs. They pointed out that, although a simulation model will accurately assess the system yield for an assumed set of operating rules, it will not assess the maximum yield that can be achieved by adopting the best possible set of operating rules for the system.

Mathematical programming techniques become popular for reservoir planning and operation, literature is available. An excellent review of the present topic is given by Yeh, W.G. [6] fallowed by Simonovic [7] and Wurbs [8] along with simulation studies, Linear Programming (LP), Dynamic Programming (DP) and Non Linear programming (NLP) are the most popular techniques are the most popular techniques.

Dahe, P.D. and Srivastava, D.K. [9] made a study on yield assessment for reservoirs based on a specified reliability and the extent of availability of supply during failure years which can lead to effective management of irrigation reservoir systems. This paper demonstrated the use of yield model for the assessment of yield of the Upper Narmada irrigation reservoir with a specified reliability and the extent of availability of supply during failure years. Dahe, P.D. and Srivastava, D.K. [10] developed the basic yield model and present a multiple yield model for a multiple reservoir system consisting of single purpose and multipurpose reservoirs. McMahon and Mein [11] and Dandy, et al. [5] the reservoir storage to be provided need only be sufficient for meeting this seasonal shortfall in inflow. Such reservoirs will have a critical period (CP) of less than 12 months and hence will empty, refill and spill at least once in any given year.

Simulation models closely represent the realistic situations and many researchers highlighted that simulation modelling is comparatively simple and reservoir managers are willing to accept the models even though they may not guarantee an optimal solution. However, in modelling with simulation, one needs to develop computer codes. The earliest simulation model associated with a system of reservoir, appearing in the literature seems to be study performed by US army corps of engineers in 1953 for an operational study for six reservoirs on the Missouri river Hall and Dracup [4]. Simulation studies were formed on the Nile valley plain Emergy and Meck [12] for problems regarding the size of the reservoirs and their operation. Maass et al. [13] demonstrated the application of simulation techniques evaluate the economic performance of a river basin.

This study presents a methodology to optimize the design of the single reservoir irrigation system by taking monthly inflow, initial storage and incorporation of failure years tries to predict the maximum possible releases using Linear programming based Yield model.

The specific objectives of the present study can be stated as fallows: 
1) To identification of failure years.

2) To develop a Linear Programming based yield model for reservoir operation for a monthly time step.

3) To draw the conclusions from the interpretation of results obtained.

\section{Study Area}

The Isapur project envisages a major single reservoir across the river Penganga, a subtributary in the Godavari river basin in the state of Maharashtra in India. It was constructed to serve the irrigation water needs of the system only (Figure 1). Total annual water requirements are 750 MCM. A data series of 28 years monthly inflow to the reservoir is available (Figure 2). The mean annual and the $75 \%$ water year dependable inflows to the reservoir are 670.98 MCM and 497.02 MCM. Based on historic data set, the estimates of the mean and the 75\% water year dependable inflows to the reservoir were obtained from the flow duration curve analysis. The gross reservoir capacity is 1241.43 MCM (active and dead storage capacities are 958.43 MCM and 283 MCM, respectively) in Table 1 . There is no provision for the flood storage.

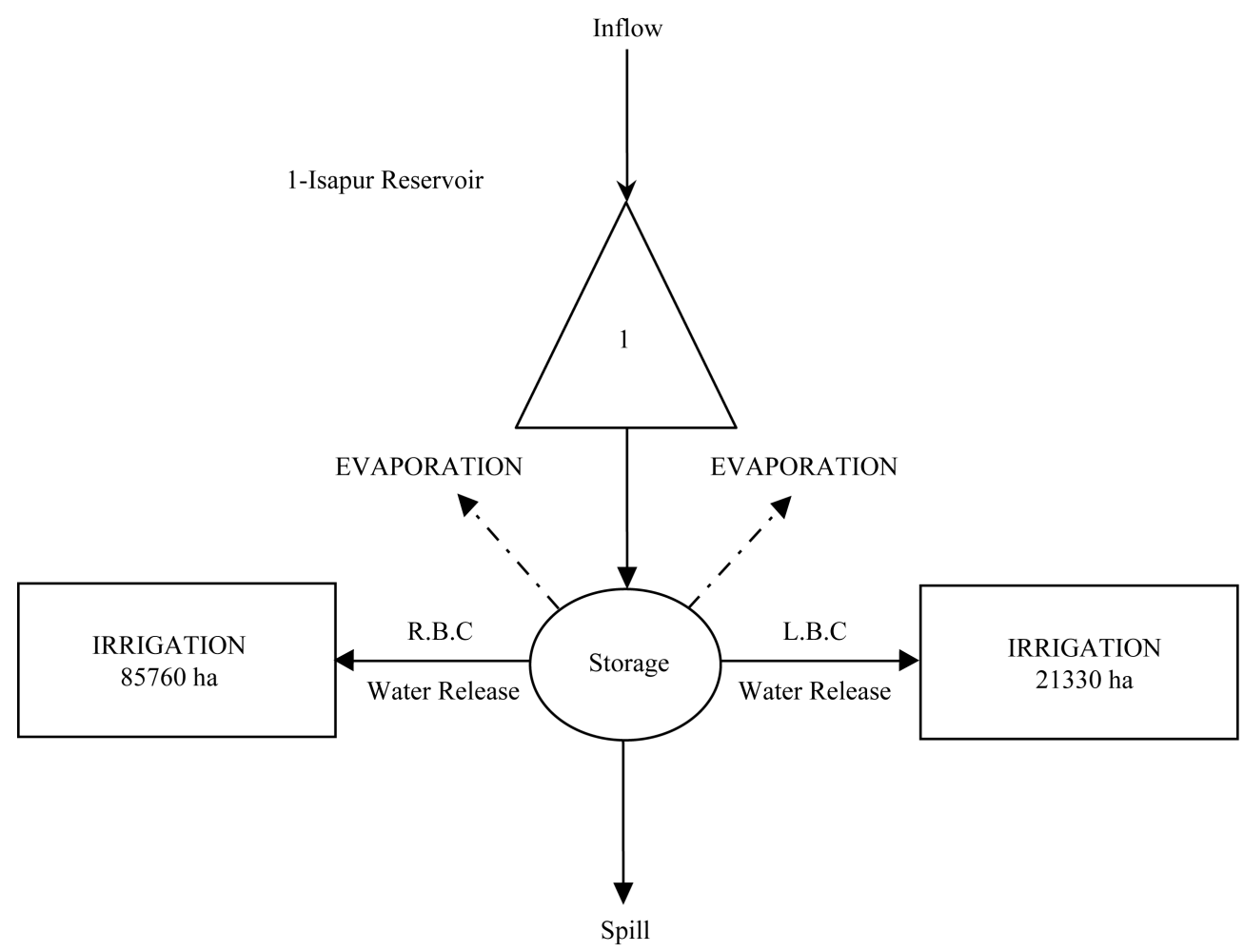

Figure 1. System model.

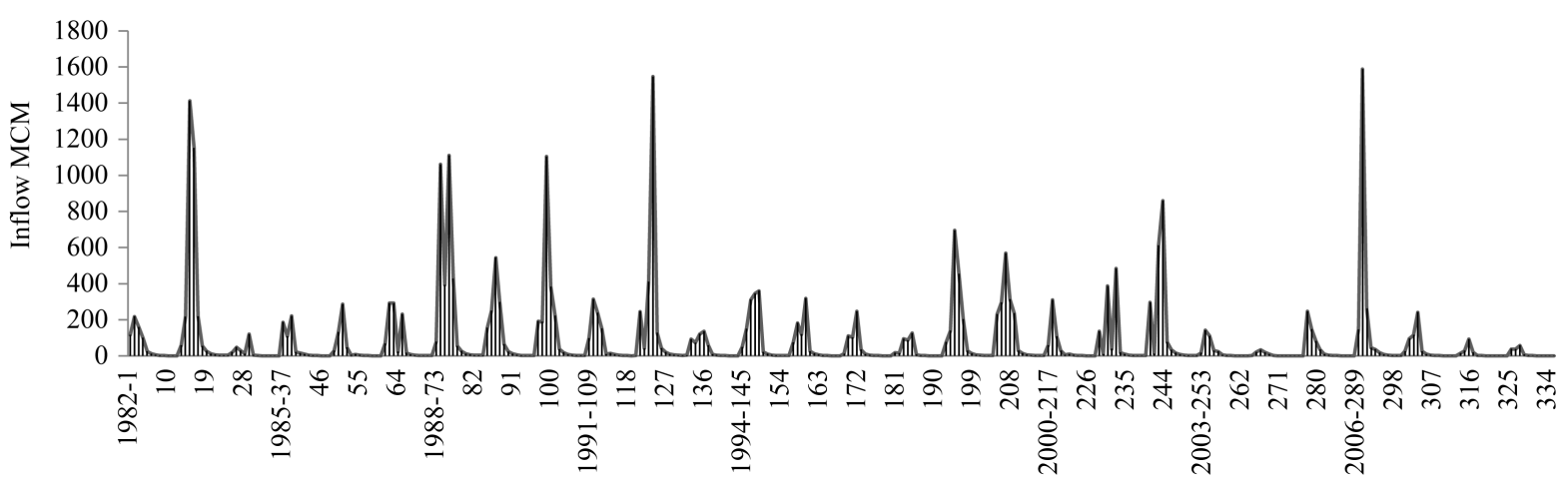

Figure 2. Penganga river inflow at isapur reservoir. 
Table 1. Silent features of Upper Penganga Project-Isapur reservoir.

\begin{tabular}{cc}
\hline Scope of Scheme & Irrigation Purpose \\
\hline Location & Penganga river at Isapur \\
Catchment area & $4636 \mathrm{Sq} \mathrm{Km}$ \\
Mean annual inflow (1982-2009) & $670.98 \mathrm{MCM}$ \\
Gross storage capacity & $1241.43 \mathrm{MCM}$ \\
Capacity of live storage & $958.43 \mathrm{MCM}$ \\
Capacity of dead storage & $283.00 \mathrm{MCM}$ \\
\hline
\end{tabular}

\section{Reservoir Yield Model}

Yield model is an implicit stochastic linear-programming model that incorporates several approximations to reduce the size of the constraint set needed to describe reservoir system operation and to capture the desired reliability of target releases considering the entire length of historical flow record. The yield model estimates overyear and within-year reservoir capacity requirements separately to meet the specified release reliability targets. The YM as given by Dahe and Srivastava [10] to determine single yield from a reservoir is as fallows.

Objective function:

$$
\operatorname{Max} \sum_{\mathrm{t}} O y^{f, p}
$$

where $O y^{f, p}=$ firm within year reservoir yields in time $t$ with reliability $p$, respectively, during the modeled critical year.

The conceptualisation and details of the yield model on which the present model development is based are presented in Loucks et al. [3]. When reservoir yield with reliability lower than the maximum reliability is to be determined, the extent of availability of yield (or the allowable deficit in yield) during failure years can be specified. This is achieved by specifying a failure fraction for the yield during the failure years. The factor $\theta_{p, j}$ is used in the model to define the extent of available yield during failure years to safeguard against the risk of extreme water shortage during the critical periods ( $\theta_{p, j}$ lies between 0 to 1 , i.e., for a complete failure year $\theta_{p, j}=0$, for partial failure year $0<\theta_{p, j}<1$, and for successful year $\theta_{p, j}=1$ ). The objective of this model is to maximize the yield for given capacity of the reservoir. Let $p$ denotes the exceedence probability for the yield. The index $j$ refers to a year and index $t$ refers to a within-year period. In this model only the firm yield is used.

The formulation of the yield model is as follows:

Objective function

Maximize $O y^{f, p}$

Constraint

1) Over-Year Storage Continuity

$$
s_{j-1}^{o}+I_{j}-\theta_{p, j} O y^{f, p}-S p_{j}-E l_{j}=s_{j}^{o} \quad \forall j
$$

The over-the-year capacity is governed by the distribution of annual stream flows and the annual yield to be provided. The maximum of all the over-the-year storage volumes is the over-the-year storage capacity. It is possible to specify a failure fraction to define the allowable deficit in annual reservoir yield during the failure years in a single-yield problem. In the above equation, $O y^{f, p}$ is the safe (firm) annual yield from reservoir with reliability $p . s_{j-1}^{o}$ and $s_{j}^{o}$ are the initial and the final over-the-year active storages in year $j$, respectively; $I_{j}$ is the inflow in year $j ; \theta_{p, j}$ is the failure fraction defining the proportion of the annual yield from reservoir to be made available during the failure years to safeguard against the risk of extreme water shortage during the critical dry periods $\left(\theta_{p, j}\right.$ lies between 0 and 1, i.e., for a complete failure year $\theta_{p, j}=0$, for a partial failure year $0<\theta_{p, j}<1$, and for a successful year $\theta_{p, j}=1$ ); $S p_{j}$ excess release (spills) in year $j$; and $E l_{j}=$ evaporation loss in year $j$.

2) Over-year active storage volume capacity 


$$
s_{j-1}^{o} \leq Y \quad \forall j
$$

The active over-year reservoir capacity $(Y)$ required to deliver a safe or firm annual yield.

3) Within-year storage continuity

$$
s_{t-1}^{w}+\beta_{t}\left(O y^{f, p}+\sum_{t} E l_{t}\right)-O y_{f, p}^{t}-E l^{t}=s_{t}^{w} \quad \forall t
$$

Any distribution of the within-the-year yields differing from that of the within-the-year inflows may require additional active reservoir capacity. The maximum of all the within-the year storage volumes is the within-theyear storage capacity. In the above equation, $s_{t-1}^{w}$ and $s_{t}^{w}$ are the initial and the final within-the-year active storages at time $t ; \beta_{t}$ is the ratio of the inflow in time $t$ of the modeled critical year of record to the total inflow in that year; and $E l_{t}$ is the within-the-year evaporation loss during time $t$. The inflows and the required releases are just in balance. So, the reservoir neither fills nor empties during the critical year.

4) Definition of estimated evaporation losses

$$
E 1_{j}=E 0+\left[s_{j-1}^{0}+\sum_{t}\left(\frac{s_{t-1}^{w}+s_{t}^{w}}{2}\right) \gamma_{t}\right] E l^{r} \quad \forall j
$$

estimated annual evaporation losses from reservoir.

5) Definition of estimated evaporation losses

$$
E 1^{t}=\gamma_{t} E 0+\left(s_{c r}^{o}+\frac{s_{t-1}^{w}+s_{t}^{w}}{2}\right) \gamma_{t} E l^{r} \quad \forall t
$$

The initial over year storage volume in the critical year $s_{c r}^{o}$ is assumed to be zero for estimated withinthe-year evaporation losses from reservoir.

6) Total reservoir capacity

$$
Y+s_{t-1}^{w} \leq Y a \quad \forall t
$$

Sum of the over-the-year and the within-the-year storage capacities is equal to the active storage capacity of the reservoir.

7) Proportioning of yield in within-year periods

$$
O y_{f, p}^{t}=K_{t}\left(O y^{f, p}\right) \quad \forall t
$$

$K_{t}$ defines a predetermined fraction of reservoir yield for the within-year yield in period $t$.

Equations (2) to (9) present the single reservoir yield model.

\section{Identification of Failure Years by Yield Model}

When the annual reservoir yield with reliability less than the maximum reliability is to be estimated, a failure in meeting the annual target is to be allowed in some years in accordance with the desired reliability. The identification of these likely failure years can be done by:

1) Visual inspection of the annual flow data at the reservoir site.

2) Making trials with the yield model, or

3) Using a simulation model.

The visual inspection is usually sufficient when the length of flow data is not very long, and the trend of annual flows can clearly indicate the critical period. A few trials with the yield model can confirm this section of failure years. If the nature of flows does not easily permit the selection of failure years, a simulation study shall be able to identify the failure years and the extent of deficits in reservoir yield during these failure years through the yield model itself.

The mathematical modifications necessary in the yield model to determine the failure years. For determination of failure years within the yield model, it is necessary to specify the unknown annual reservoir yield failure amount in a possible failure year. This can be accomplished by introducing an additional variable $\left(F_{j}\right)$ in each year. Once such a variable is introduce, it is possible to replace the term $\left(\theta_{p, j} O y^{f, p}\right)$ by the term $\left(O y^{f, p}-F_{j}\right)$ 
in each of the over-year continuity equation. This shall eliminate the need to identify the failure years prior to the model solution. Next it is necessary to restrict the number of failure years in accordance with the desired reliability of annual reservoir yield. The number of failure years shall be necessary for a desired annual reliability shall be denoted by $N_{f}$. Following description outlines the necessary modifications and the additional constraints to be incorporated in the yield model.

Define

$F_{j}=$ unknown reservoir yield failure amount it a possible failure year.

$N_{f}=$ number of failure years required for a desired annual reliability.

The following modification is necessary in the over-year constraints:

The term $\left(\theta_{p, j} O y^{f, p}\right)$ is to be replaced by $\left(O y^{f, p}-F_{j}\right)$.

Additional constraints are necessary in the yield model to ensure

1) That none of the shortages exceed $\left(1-\theta_{p, j}\right)$ times the annual reservoir yield, and

2) That at most there are $N_{f}$ failure years for achieving the desired reliability.

Accordingly, the necessary modifications and additional constraints are presented below:

$$
\begin{gathered}
s_{j-1}^{o}+I_{j}-\theta_{p, j} O y^{f, p}-F_{j}-S p_{j}-E l_{j}=s_{j}^{o} \quad \forall j \\
F_{j} \leq(1-0.75) O y^{f, p} \quad \forall j \\
\sum_{j} F_{j} \leq N_{f}(1-0.75) O y^{f, p}
\end{gathered}
$$

\section{Discussion on Results}

The observed historical inflows for 28 years at the Isapur reservoir were used in computation of the yields from the reservoir with an active capacity of 958.43 MCM (project value). Out of these a set of 6 lowest flow years $(\approx 25 \%$ of the Years) were assumed as the failure years, determined modified method of identified failure years yield model. Thus remaining 22 years were successful years representing $75 \%$ annual project reliability. Twenty eight over year and twelve within year periods were considered for analysis. For the value of $\beta_{t}$ 's based on average monthly flows has been considered for the analysis, presented in Table 2, the maximum flow of 0.3105 (31.05\%) is recorded in the month of August. The within year yields from the reservoir for irrigation in a month are represented as a fraction of its annual yield. This fraction is the ration between the monthly and the annual crop water requirements, which, in this case, has a minimum value of 0.0076 in the month of June and maximum of 0.1466 in the month of August. The values of parameters $\gamma_{t}$ (the fraction of the annual evaporation volume loss that occurs in period $t$ ) at reservoir site and the maximum value of 0.1588 in the month of May and minimum value of 0.0544 in the month of December are presented in Table 2.

With the provision of $\theta_{p, j}$, the extent of failure in the annual yield from the reservoir during failure years was monitored as clear guidelines were not established for deciding its value. The value of $\theta_{p, j}$ for the project was

\begin{tabular}{|c|c|c|c|c|c|c|c|c|}
\hline \multicolumn{2}{|c|}{ Parameters } & \multirow{2}{*}{ Parameters } & \multicolumn{6}{|c|}{ Within-year time period in months } \\
\hline$E 0$ & $E 1^{r}$ & & JUNE & JULY & AUG & SEP & OCT & NOV \\
\hline \multirow{7}{*}{64.67} & \multirow{7}{*}{0.117} & $\beta_{t}$ & 0.0812 & 0.2044 & 0.3105 & 0.2498 & 0.1193 & 0.0171 \\
\hline & & $\gamma_{t}$ & 0.0976 & 0.0729 & 0.0611 & 0.0638 & 0.0604 & 0.0600 \\
\hline & & $K_{t}$ & 0.0076 & 0.1103 & 0.0894 & 0.1085 & 0.0700 & 0.1466 \\
\hline & & Parameters & DEC & JAN & FEB & MARCH & APRIL & MAY \\
\hline & & $\beta_{t}$ & 0.0083 & 0.0037 & 0.0020 & 0.0013 & 0.0011 & 0.0013 \\
\hline & & $\gamma_{t}$ & 0.0544 & 0.048 & 0.0802 & 0.1109 & 0.1319 & 0.1588 \\
\hline & & $K_{t}$ & 0.1165 & 0.1083 & 0.0613 & 0.0312 & 0.0428 & 0.1075 \\
\hline
\end{tabular}

Table 2. Within-year inflow approximation, irrigation and evaporation parameters used in the yield model for Isapur reservoir in Penganga river. 
determined using the YM with an objective to minimize its value. In single purpose reservoir, irrigation originnally being the main project target was considered as a single yield or firm yield from the reservoir. The annual project reliability for irrigation was kept equal to $75 \%$. The value of $\theta_{p, j}$ was found to increase with the decrease in the annual yield from the reservoir. The optimal minimum value of $\theta_{p, j}$ obtained in this case was 0.5 . The value of $\theta_{p, j}$ adopted for the project was 0.5 , this gives less spill and higher utility factor. Results of simulation studies for the single yield and given annual project reliability have shown that for $\theta_{p, j}$ equal to 0.5 .

The following two options were used considering the single yield with identification of failure years (simulation models failure years and modified method for yield model failure years) and maximization of the total annual reservoir yield.

1) The simulation model gives the failure years in the analysis $5^{\text {th }}, 22^{\text {nd }}, 23^{\text {rd }}, 24^{\text {th }}, 27^{\text {th }}$ and $28^{\text {th }}$ years are the critical years and remaining are the successful years. These failure years are considering for the yield analysis in the yield model, annual yield is obtained of 520.127 MCM from the reservoir requiring the over-the-year reservoir storage capacity of 608.764 MCM.

2) The modified method is incorporate in the yield model for evaluation of failure years, in these cases the six failure years $\left(22^{\text {nd }}, 23^{\text {rd }}, 24^{\text {th }}, 26^{\text {th }}, 27^{\text {th }}, 28^{\text {th }}\right)$ and also amount of failure (F22, F23, F24, F26, F27 and F28) could be identified. Thus it is possible to identify the failure years explicitly in the yield model. The annual yield is obtained in this case is $\mathbf{5 2 7 . 8 5 4} \mathbf{M C M}$, this required an over-the-year reservoir storage capacity of 604.177 MCM.

The yield model with the yields Option 2 given above has gives the higher annual yield than the Option 1 annual yield (Figure 3).

This modification in the model is advantageous in following respects in case of single reservoir problems:

1) It can identify the correct failure years, and hence can improve the accuracy in estimation of annual reservoir yield.

2) It can provide the estimate of extent of annual reservoir yield failure (deficit) in each failure year. The amount of deficit in each failure year is not compelled to be equal (as in case when the failure fraction $\theta_{p, j}$ is introduced). The deficits in annual reservoir yield in different failure years shall be in accordance with the nature of inflows, and the within-year distribution of annual reservoir yield. Hence the economic consequence of deficits can be included in the objective function.

3) Though the number of failure years may not exactly correspond to the number for a predefined reliability, this modification can serve as a means of estimating the optimal reliability (reliability considered as a decision variable) with respect to economic benefits and losses.

\section{Conclusion}

This modification in the yield model to determine the failure years can be effectively applied to single reservoir

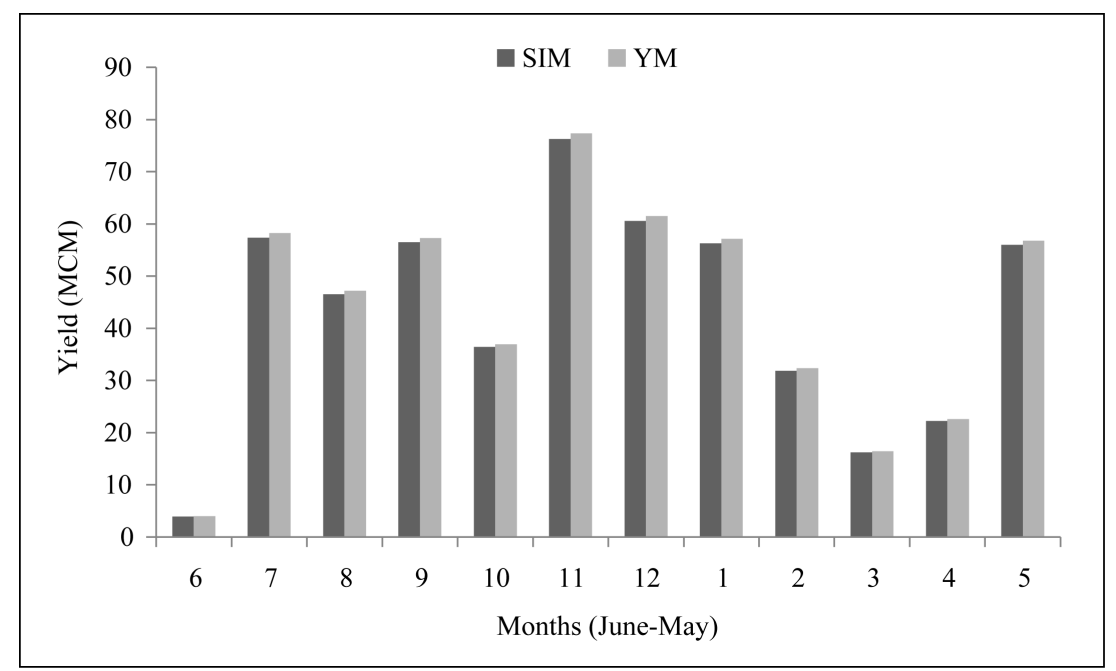

Figure 3. Comparison of within-year storages and yields (Simulation and YM). 
problems when the impact of deficits in annual reservoir yield on the objective is to be evaluated. The objective in such cases may be to minimize the deviations from a given target or to maximize the net benefits by applying penalties for the deficits. It can definitely be used for determining the correct failure years at individual reservoir problem. This exercise is necessary to arrive at a common set of failure years, before the yield model is applied to the reservoir system. This can definitely save the additional effort of using simulation for determining the failure years.

\section{References}

[1] Jacoby, H.D. and Loucks, D.P. (1972) Combined Use of Optimization and Simulation Models in River Basin Planning. Water Resources Research, 8, 1401-1414. http://dx.doi.org/10.1029/WR008i006p01401

[2] Viessman Jr., W., Lewis, G.L., Yomotovian, I. and Viessman, N.J. (1975) A Screening Model for Water Resources Planning. Water Resource Bulletin, 11, 245-255. http://dx.doi.org/10.1111/j.1752-1688.1975.tb00677.x

[3] Loucks, D.P., Stendiger, J.R. and Haith, D.A. (1981) Water Resource Systems Planning and Analysis. Prentice-Hall, Inc., Englewood Cliffs.

[4] Hall, W.A. and Dracup, J.A. (1970) Water Resources System Engineering. McGraw Hill Inc., New York.

[5] Dandy, G.C., Connarty, M.C. and Loucks, D.P. (1997) Comparison of Methods for Yield Assessment of Multipurpose Reservoir Systems. Journal of Water Resource Planning and Management, ASCE, 123, 350-358. http://dx.doi.org/10.1061/(ASCE)0733-9496(1997)123:6(350)

[6] Yeh, W.G. (1985) Reservoir Management and Operations Models: A State-of-the-Art Review. Water Resources Research, 21, 1797-1818. http://dx.doi.org/10.1029/WR021i012p01797

[7] Simonovic, S.P. (1992) Reservoir System Analysis: Closing Gap between Theory and Practice. Journal of Water Resource Planning and Management, ASCE, 118, 262-280. http://dx.doi.org/10.1061/(ASCE)0733-9496(1992)118:3(262)

[8] Wurbs, R.A. (1993) Reservoir Management and Operations Models. Journal of Water Resource Planning and Management, ASCE, 119, 455-472. http://dx.doi.org/10.1061/(ASCE)0733-9496(1993)119:4(455)

[9] Dahe, P.D. and Srivastava, D.K. (2000) Assessment of Reliable Reservoir Yield for an Irrigation Project. Proceeding of the National Seminar on Irrigation Strategies_-Present and Future, Irrigation Management and Training Institute, Thuvakudy, Tiruchirapalli, Tamilnadu, India, Volume Section on Theme II, 5-15.

[10] Dahe, P.D. and Srivastava, D.K. (2002) Multipurpose Multiyield Model with Allowable Deficit in Annual Yield. Journal of Water Resource Planning and Management, ASCE, 128, 406-414. http://dx.doi.org/10.1061/(ASCE)0733-9496(2002)128:6(406)

[11] McMohan, T.A. and Mein, R.G. (1978) Reservoir Capacity and Yield. Elsevier Publishing Company, Amsterdam.

[12] Emery, D.A. and Meek, B.I. (1960) The Simulation of the Complex Reservoir System. In: Rosenstiel, P. and GhouilaHouri, A., Eds., Les Choix Economiques, Dunod, Paris, 273-255.

[13] Maass, A., Hufschmidt, M.M., Dorfman, R., Thomas Jr., H.A., Marglin, S.A. and Fair, G.M. (1962) Simulation Techniques for Design of Water-Resource Systems in Design of Water Resources Systems. In: Mass, A., et al., Harvard University Press, Cambridge. http://dx.doi.org/10.4159/harvard.9780674421042 
Scientific Research Publishing (SCIRP) is one of the largest Open Access journal publishers. It is currently publishing more than 200 open access, online, peer-reviewed journals covering a wide range of academic disciplines. SCIRP serves the worldwide academic communities and contributes to the progress and application of science with its publication.

Other selected journals from SCIRP are listed as below. Submit your manuscript to us via either submit@scirp.org or Online Submission Portal.
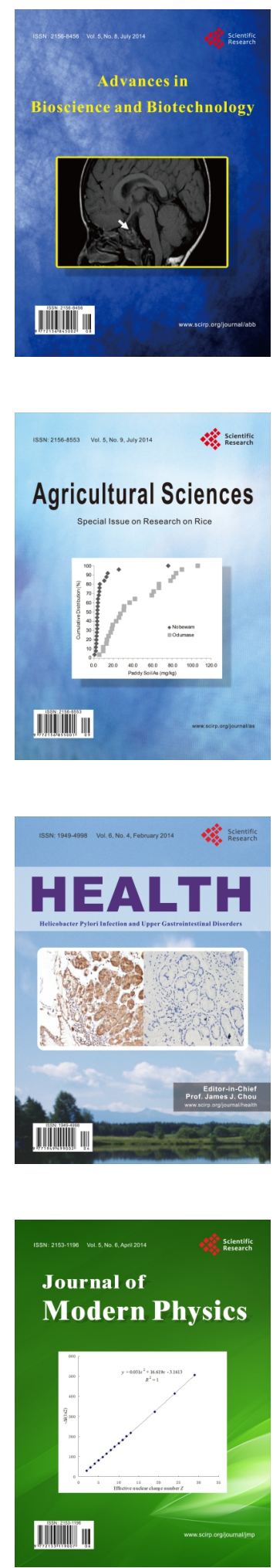
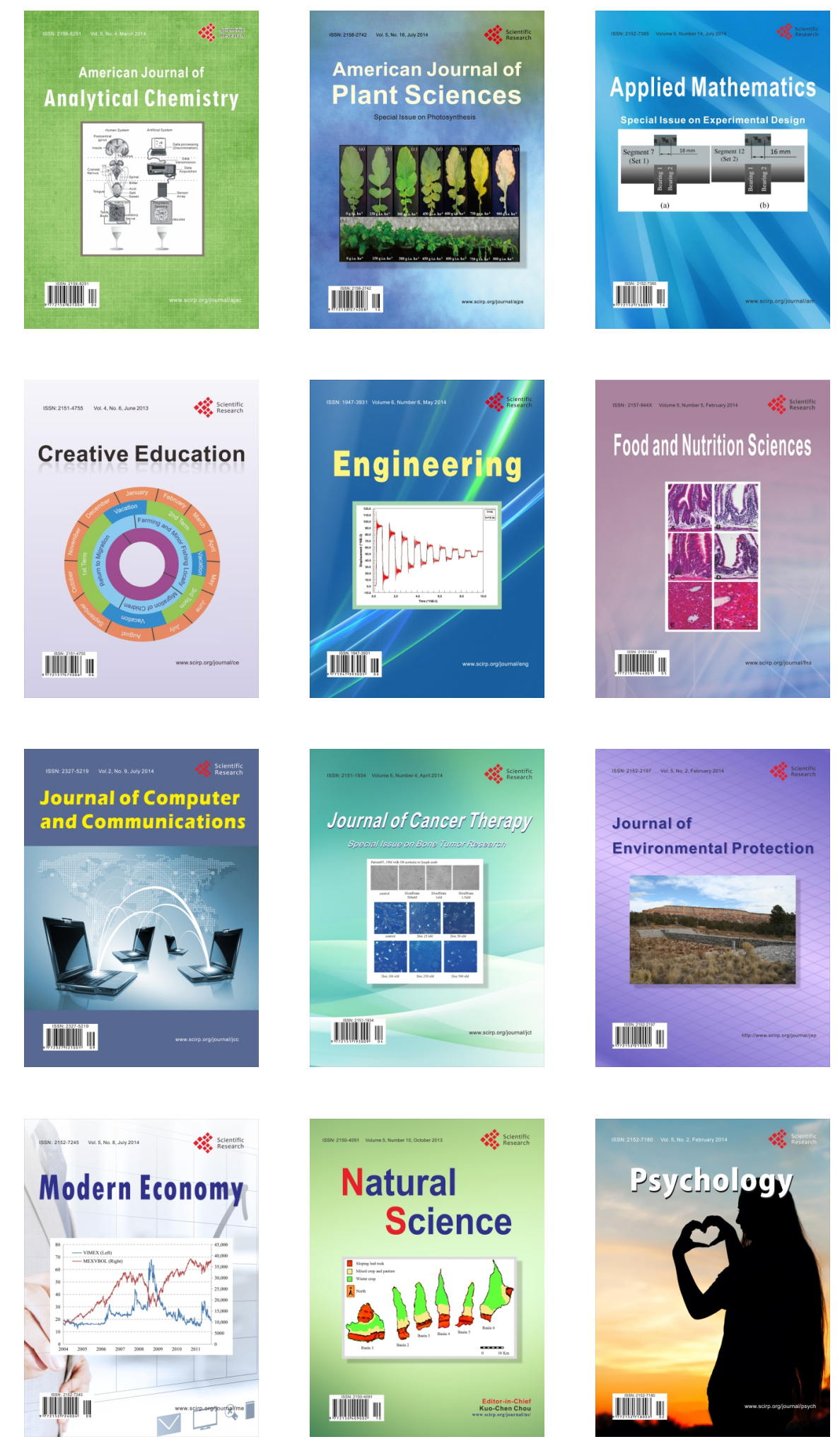